\title{
Female-Initiated Prevention Methods (FIPM) in Kenya: Focus on the female condom
}

Martha Brady

Population Council

Follow this and additional works at: https://knowledgecommons.popcouncil.org/departments_sbsr-pgy

Part of the Demography, Population, and Ecology Commons, Family, Life Course, and Society Commons, Gender and Sexuality Commons, International Public Health Commons, Medicine and Health Commons, and the Women's Health Commons How does access to this work benefit you? Let us know!

\section{Recommended Citation}

Brady, Martha. 2008. "Female-Initiated Prevention Methods (FIPM) in Kenya: Focus on the female condom," Project brief. New York: Population Council. 


\section{(1) Population Council}

\section{PROJECT BRIEF}

\section{FEMALE-INITIATED PREVENTION METHODS IN KENYA: FOCUS ON THE FEMALE CONDOM}

$\mathrm{T}$ he female condom (FC) is the only female-initiated prevention product on the market today that provides simultaneous protection against pregnancy and sexually transmitted infections, including HIV. Although the FC has been available for more than a decade, it remains limited in supply, not readily available, and, consequently, underutilized.

Obstacles to the widespread availability and use of the female condom, while frequently mentioned, are often generalized (e.g., high cost, resistance of partners, or simple unavailability). With the upcoming second generation of FCsand, ultimately, microbicides-being added to the list of female-initiated prevention methods, the need to overcome these impediments with concrete solutions is critical. Specific obstacles to FC use must be determined, effective ways to distribute and access FC identified, and a renewed sense of innovation generated. Government and donor commitment to long-term, sustained supply and program support is essential, both for the successful establishment of the FC and to help pave the way for future HIV prevention products for women. The Population Council and its partnersLiverpool VCT, Family Health Options Kenya, DelMonte, and Unilever-will stimulate action and generate evidence through innovative program experimentation and by mapping the female condom landscape in Kenya.
Testing Different Programmatic Entry Points Most descriptive and evaluative literature on the FC explores either one particular service-delivery approach (e.g., public sector family planning/reproductive health programs, social marketing programs) or a specific target population (e.g., commercial sex workers); few have attempted to look broadly at the potential constellation of program entry points and identify the specifics of working within them. Acceptability of the FC to users has been established through research in many countries, but no effort has been made to compare different programmatic delivery mechanisms and service delivery models. The Female-Initiated Prevention Methods (FIPM) Project explores the appropriateness, feasibility, and relative effectiveness of three different means of delivering female condom services in Kenya, namely: a) voluntary counseling and testing centers, b) Family Health Options of Kenya centers, and c) workplace HIVIAIDS programs.

Voluntary Counseling and Testing (VCT) Centers Male condoms are available at most VCT centers, but female condoms have not been fully integrated into counseling services. The FIPM Project trained VCT staff to integrate female condoms into existing service protocols, including during counseling about strategies to prevent transmission of HIV. The FC is now offered alongside the male condom as part of an "enhanced package of protection."

Family Health Options of Kenya (FHOK) Centers Male condoms are available at most family planning centers in Kenya for the purpose of contraception, and they offer the added advantage of protection from HIV. Female condoms have had 


\section{(2) Population Council}

limited integration into family planning services in Kenya. Selected FHOK sites will offer the FC to all women who wish to use it. The FC represents an important tool for those clients seeking to prevent sexually transmitted infections.

Private Sector Workplaces

Two private sector workplaces, DelMonte and Unilever, have active HIVIAIDS prevention programs. Both of these workplaces are incorporating the FC into their HIVIAIDS messages and peer education programs, and female condoms are being provided through condom dispensers along with male condoms at these sites.

Female Condom Training for Peer Educators, Counselors, and Service Providers

Peer educators and counselors from the selected service delivery sites (VCT, FHOK, and workplace) received intensive training on the $\mathrm{FC}$ by an internationally recognized master trainer. The trainer used a standardized curriculum encompassing reproductive health and HIVIAIDS topics, as well as broader issues of male involvement in reproductive health and negotiating the use of condoms. Following this training, both male and female condoms are now available to clients at all sites.

\section{Key Questions}

Qualitative and quantitative data-collection techniques are being used to gather information from providers, clients, and program managers.

Questions include:

1. What are the gaps in knowledge about the female condom among clients and providers?

2. What "triggers" do women and men respond to regarding the promotion of the $\mathrm{FC}$ in various distribution sites (e.g., messages, types of providers, ease of access, whether FCs are associated with family planning)?
3. What supports (training, advocacy, policy, civil society) are needed for successful female condom promotion and distribution?

4. To what extent does the manner of providing information, supply, price, site, type of provider, etc., promote willingness to use the FC?

Mapping the Female Condom Policy Landscape While research has demonstrated that the FC is an effective, acceptable, and desired dual protection product (against pregnancy and HIV), little is known about what mix of policy initiatives and service settings provide the greatest access to and availability of the FC. In Kenya, both the National HIVIAIDS Strategic Plan and the National Condom Policy and Strategy acknowledge that FCs are a valuable female-initiated prevention product. These policy documents further state that priority should be given to ensuring adequate national supplies of and accessibility to FCs; however, implementation of these policies is challenging. Despite supportive policies and many potential avenues for distribution, access to female condoms remains limited in Kenya.

The FIPM Project has developed tools for mapping the FC landscape in Kenya. Interviews with key stakeholders will explore how features of the FC influence program efforts, what attitudes are prevalent among decisionmakers about the FC, what target populations may be most appropriate in Kenya, and which cultural factors influence decisionmaking among policymakers, providers, and FC users. FC supply chains and their impediments will also be explored.

Findings from this research will inform a more sophisticated and acceptable delivery of the FC to Kenyan women and will suggest the most effective pathways to enhance FC delivery programs, as well as prepare for future female-initiated prevention methods in Kenya.

FOR MORE INFORMATION ON THE FEMALE-INITIATED PREVENTION METHODS PROJECT IN KENYA, CONTACT MARTHA BRADY, MBRADY@POPCOUNCIL.ORG FOR MORE INFORMATION ABOUT THE POPULATION COUNCIL'S WORK ON
HIV AND AIDS, SEE WWW.POPCOUNCIL.ORG/HIVAIDS/PROGRAM.HTML

(C) 2008 The Population Council, Inc

Population Council, One Dag Hammarskjold Plaza, New York, NY 10017 USA E-mail: pubinfo@popcouncil.org www.popcouncil.org 